\title{
Dining House Information System (Case Study: Tengku Di Ujung, Simeulue District)
}

\author{
Ayat Hasanul Alfarisi * \\ Information Technology Faculty, STMIK Abulyatama Aceh \\ Email: ayatalfarisi@gmail.com
}

Received: 11 January 2021; Accepted: 18 March 2021; Published: 1 April 2021

\begin{abstract}
The Tengku Diujung restaurant is one of the tourist destinations that is frequently visited by tourists because the restaurant has a mainstay menu that is in demand by many visitors, one of which is lobster noodles. However, each sales report still records data manually, sometimes experiencing errors due to inaccuracies in recording data. The formulations in this study are; how to manage all data on reports of receipts, orders, and sales or expenditures of goods, and whether employees are easy to find data, and how to manage data on receipts, orders, and sales or expenditures of goods. To complete the data needed in the preparation of this study, the authors use writing sources, namely; Library Research, Field Research, and Interviews and Observatories. From the results of the discussion on "Inventory Information System at the Tengku Diujung Restaurant (Simeulue Regency)" the author can conclude that the use of a manual system has limitations in selling goods. This information system, makes it easier for the restaurant to present information about revenue, ordering, and sales data to its customers. Although it requires a lot of money, it is worth the ease with which it is obtained, and designing this application will speed up the production of receipts, orders, and sales reports. The results of this study are the development of an Inventory Information System application with 9 (nine) inputs in the form of; data on goods, suppliers, customers, receipts, expenses, stocks, transactions, and application users. There are 6 (six) output designs consisting of; goods data, suppliers, customers, receipts, expenses, and stock reports.
\end{abstract}

Index Terms: Information System; Inventory Report; Sales; Desktop.

\section{Introduction}

The current development of information technology, it has created new types and business opportunities where business transactions are increasingly being computerized [1,2]. The Tengku Diujung restaurant is one of the tourist destinations that is often visited by tourists because the restaurant has a mainstay menu that is in demand by many visitors, one of which is lobster noodles. However, every sales report still records data manually, sometimes having errors due to inaccuracy in recording data. If something like this happens, the recorded data is not in accordance with the actual report and will result in losses for the manager. For that, we need a means that will make it easier to get real information and reduce errors. In this case, every activity that occurs, especially the making of sales reports requires a system that runs computerized. In conducting the writing of this research the writer has several objectives, as for the objectives are; 1) To get a clear picture of how the system of reports of receipts, orders, and sales or expenditures of goods is applied to the Tengku Diujung Restaurant (Simeulue Regency), 2) To make a design for a desktop-based sales reporting system, 3) To make it easier to find information that is required in terms of reports of receipts, orders and sales or expenditures of goods, and 4) Make it easier to make reports of receipts, orders, and sales or expenditures of goods.

\section{Research Method}

To complete the data needed in the preparation of this study, the authors use the following sources of writing:

a) Library Research

To obtain data that help this research, the author collects reference material in the form of theoretical references from books and other reading sources related to the writing of this study $[3,4,5]$.

b) Field Research

This research was conducted based on direct observation from the research site so that the data used in this study were the real data obtained when the research was conducted $[6,7]$.

In this field study the author uses two techniques, namely: 
a) Interview

At this stage, the writer interviewed directly with the owner/leader of the Tengku Diujung Restaurant and the employees as well as the person in charge of the monthly report so that the writer knew more clearly about the problems faced today [8].

b) Observatoin

In collecting data, the authors looked directly at the restaurant to get a real picture of the work process and the running system $[9,10]$.

The author directly conducted research at the Tengku Diujung Restaurant which is located at Jln. Tgk. At the end of Simeulue Cut District, Simeulue Regency for approximately one month starting from December 11 to January 8, 2018. The time required to process each sales data at the Tengku Diujung Restaurant is around 5 minutes according to the number of sales. To complete the report every day takes 10 minutes.

$$
\begin{array}{ll}
\mathrm{T} & =(\mathrm{tr}+\mathrm{tp}) \times \mathrm{vr} \\
£ & =(5+10) \times 1 \\
& =15 \text { minutes }
\end{array}
$$

Meanwhile, to complete a minimum of 2 reports it takes time, namely:

$\mathrm{T}$

$$
\begin{aligned}
& =(\operatorname{tr}+\mathrm{tp}) \times \mathrm{vr} \\
& =(5+10) \times 2 \\
& =30 \text { minutes }
\end{aligned}
$$

Information :

T : The time it takes to complete one type of report,

$\operatorname{Tr} \quad$ : Average time to input one type of sales data report

Tp : Adjustment time to complete one report unit,

$\mathrm{Vr} \quad$ : Average volume of work over a certain period of time

The process of the desktop-based sales and ordering system at the Tengku Diujung Restaurant is basically very different from the old system, what distinguishes it is the media and the equipment it uses. In inputting sales data and other data, a new design system uses a computerized application. The way the system performs is to get the data input results listed in a file. More details on the design of the new system can be seen in the following figure:

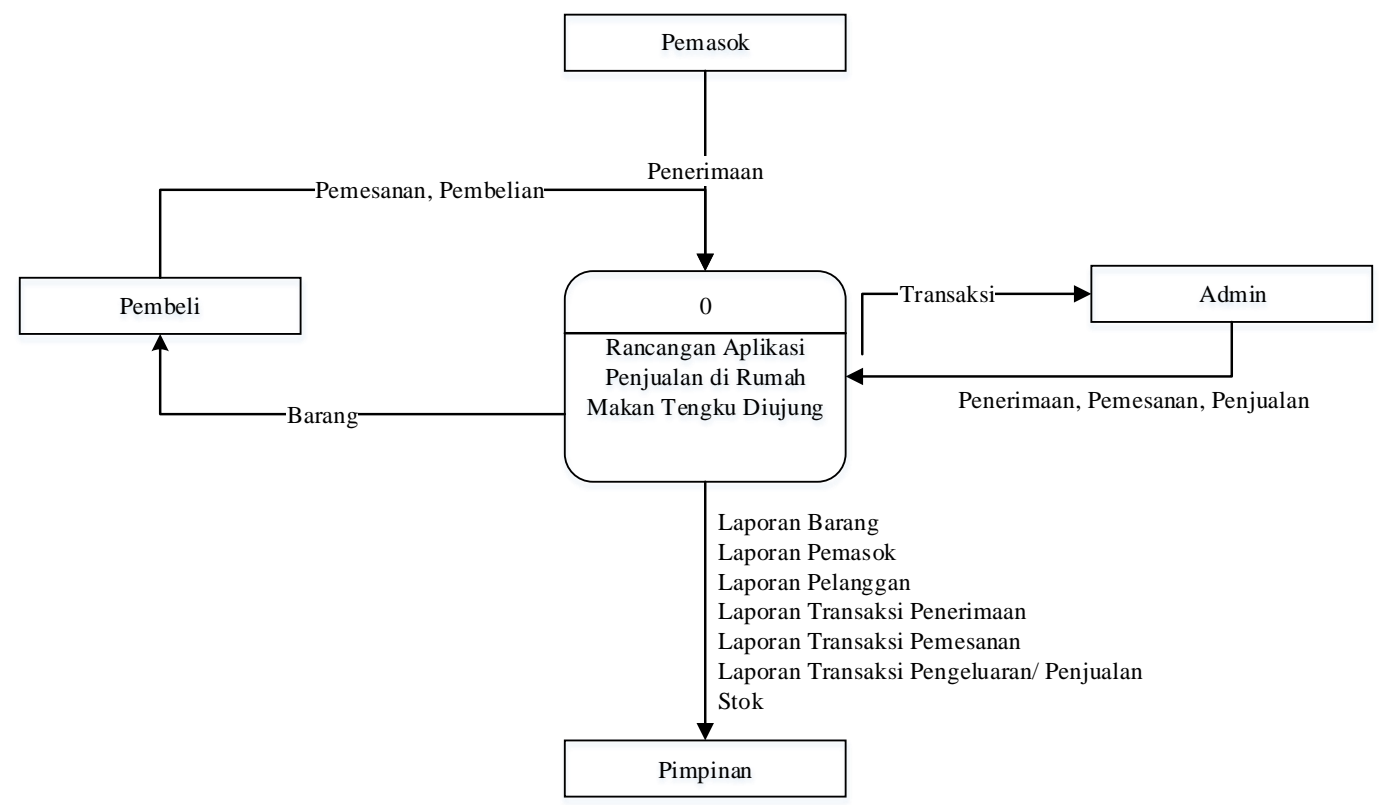

Fig.1. Design System Context Diagram

From Figure 1, it is clear that in the Design System Context Diagram, starting from the admin inputting goods data, supplier data, and customer data, then every buyer transaction or referred to as a customer will be recorded on expenses and every transaction with suppliers is recorded at the receipt of goods. After all the data is processed, the purchase recap file is sent to the leader, after which the system provides a recap of the entire sales transaction. Then the data that has been stored in each file will be processed in the process of making a report where the results of the report will be submitted to the leadership. For more details, the tiered diagram of the new design system can be seen in the following figure: 


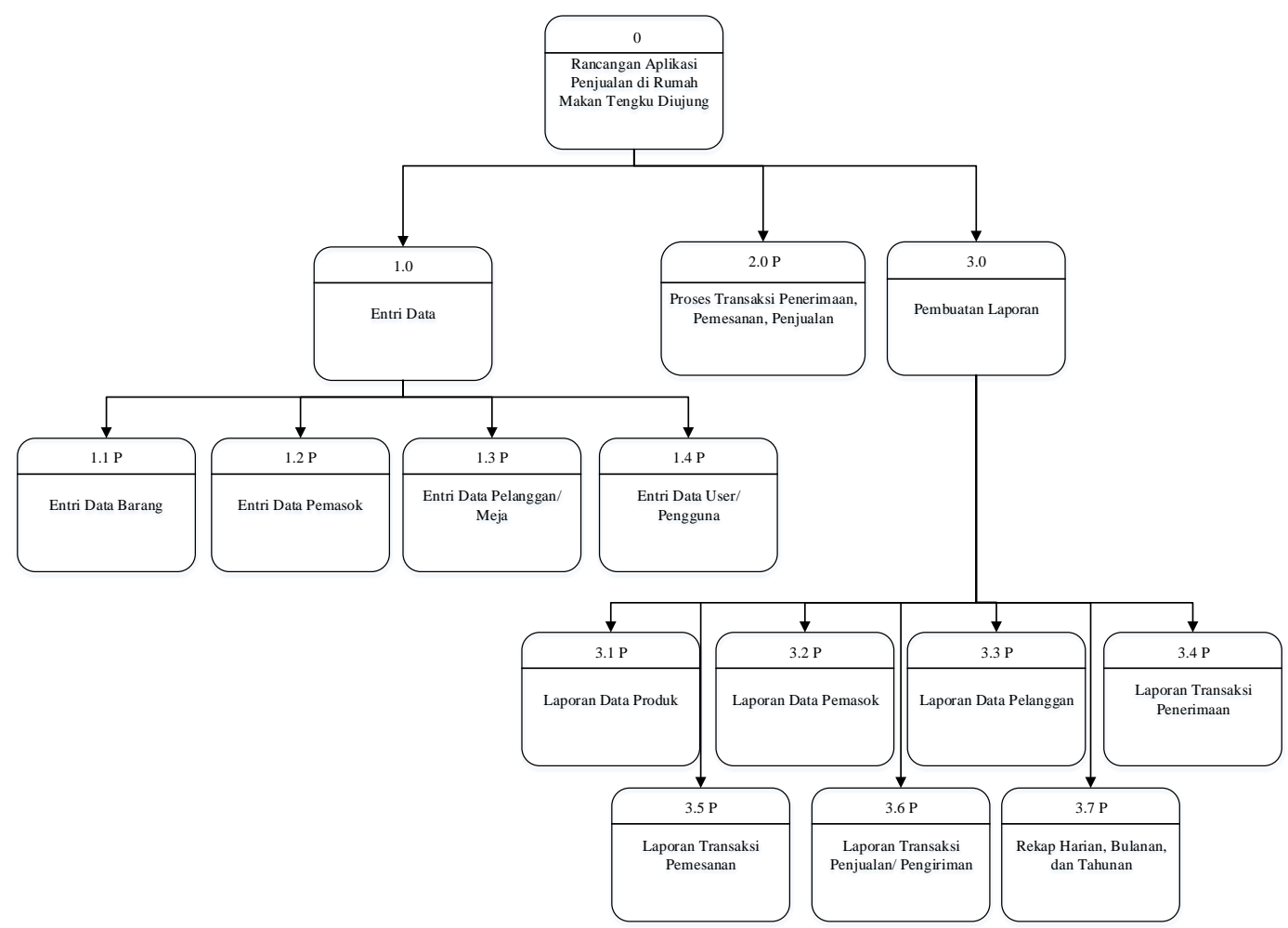

Fig.2. Tiered Diagram System Design

Based on Figure 2, above, it can be seen that in the tiered diagram the Design System above consists of three processes, namely the data entry process, the transaction process, and the report generation. In data entry, there are eight sub-systems, while the report-making process consists of six sub-systems.

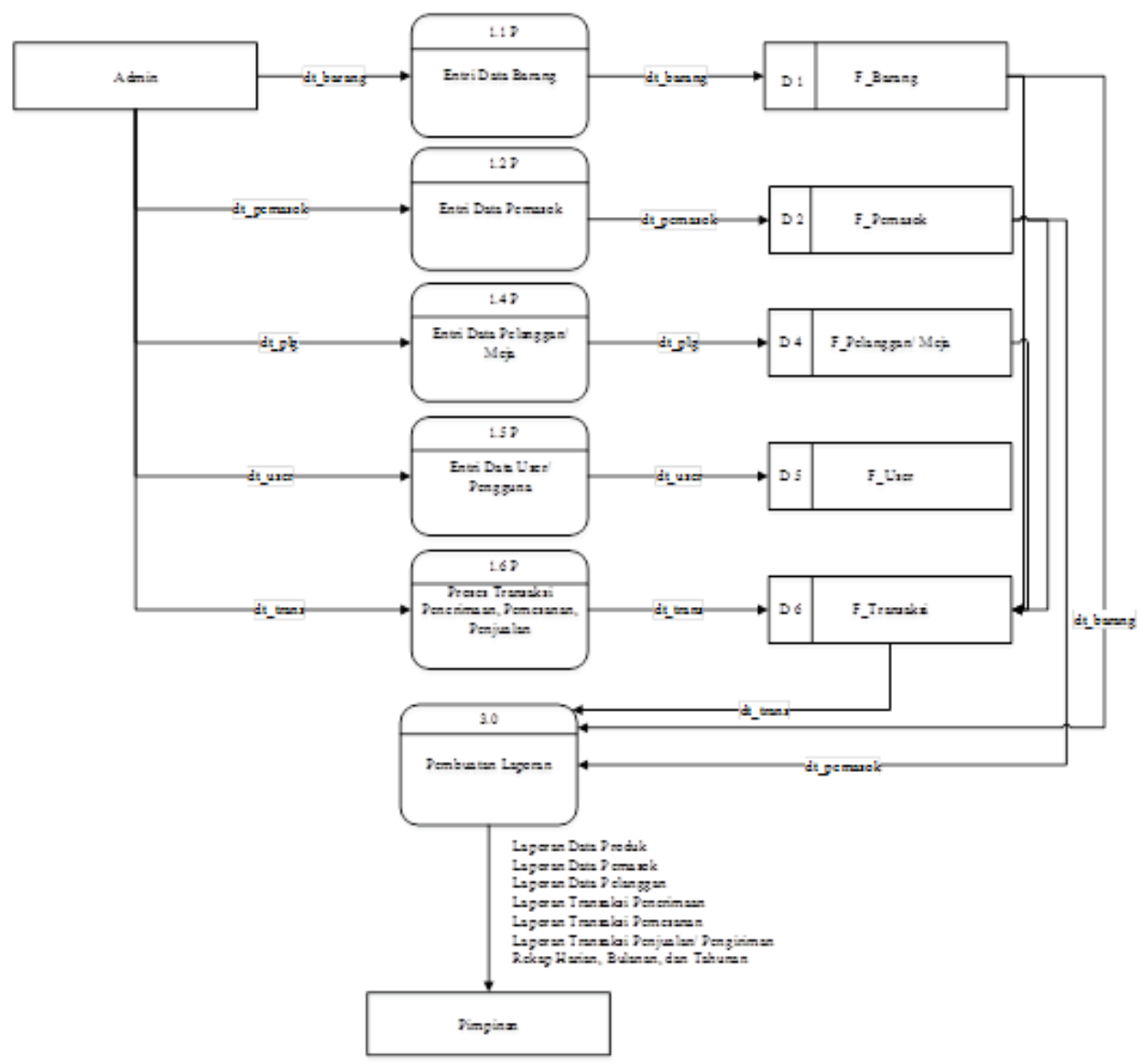

Fig.3. Design level 0 data flow diagram System Design 
Based on Figure 3, in the Level 0 Data Flow Diagram Design System, starting from the Admin collecting data, where the data is stored in each file, after that the buyer enters the data, where all the data will result in a purchase transaction to be recorded into several files, where the file is will be a report that will be submitted to the leadership. For more details about the sales design process at the Tengku Diujung Restaurant, it can be explained in the level 1 data flow diagram the process no 1 design system.

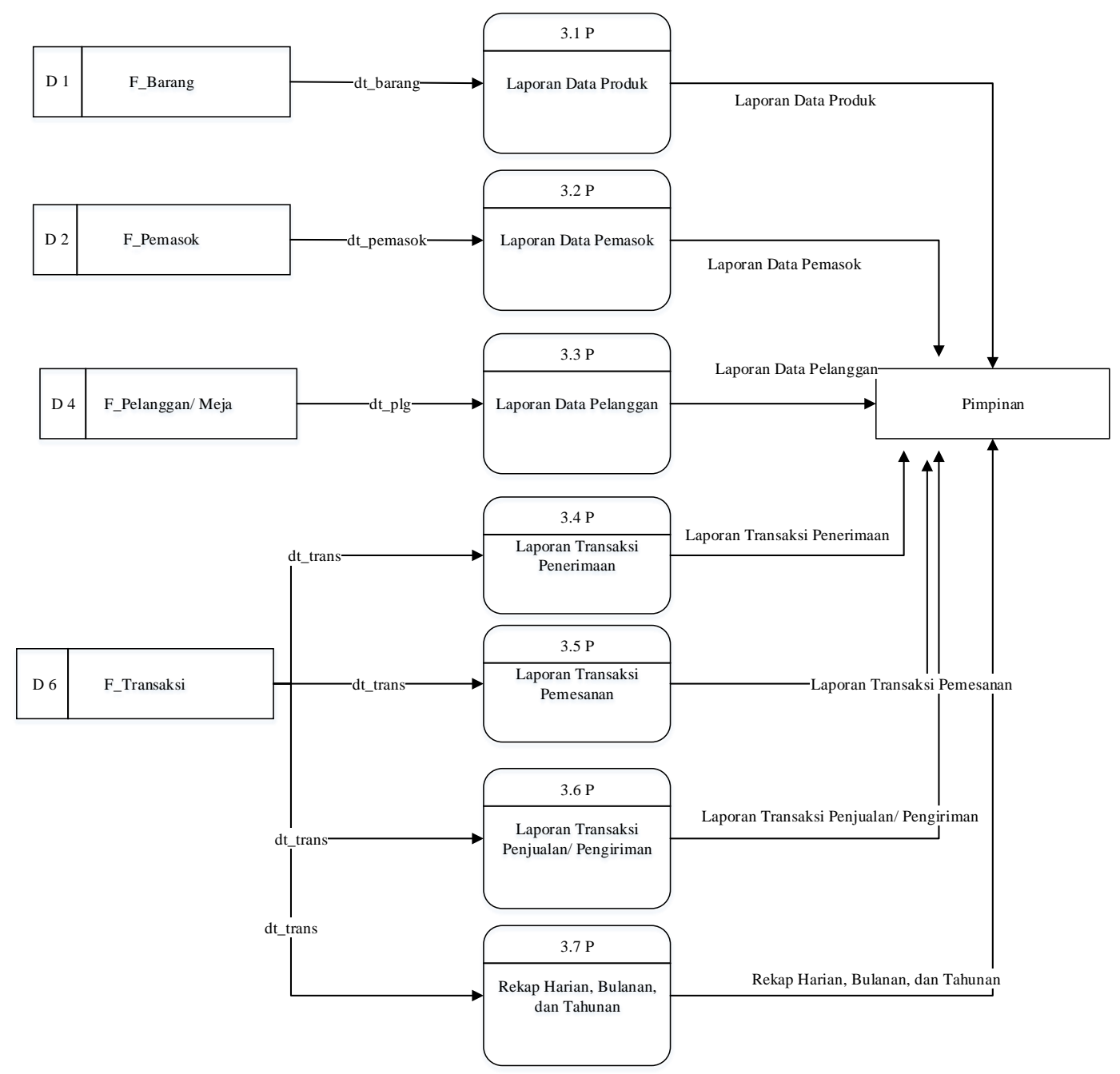

Fig.4. Level 1 Data Flow Diagram Process No. 1 Design System

Based on Figure 4, Level 1 Data Flow Diagram Process No. 1 System The design above consists of six processes. Furthermore, the data is recorded and stored in the respective datastore files for processing in the next process.

\section{Result and Discussion}

The design of the inventory information system software at the Tengku Diujung Restaurant that the writer designed consists of several stages, namely the input design, output design, database relation design, process design, control design, time design, labor design, and cost design. The writer hopes that this design will make it easier for each user, especially the sales section of the Tengku Diujung Restaurant. For more details, the stages of the design can be seen in the following explanation. The output design consists of several reports such as;

a. Item / Menu Data,

b. Supplier Data,

c. Customer Data / Guest Desk

d. Receipt data, divided into

1. Daily Report

It is information on goods receipt transactions from suppliers which are recorded every day and made in the form of daily reports.

2. Monthly report 
It is information on goods receipt transactions from suppliers which are recorded every day and made in the form of monthly reports.

3. Annual report

It is information on goods receipt transactions from suppliers which are recorded every day and made in the form of an annual report.

e. Expenses or sales data, divided into

1. Daily Sales Data, every day there is a sale made by the admin and cashier, a daily sales report will be generated to be given to the leader.

2. Monthly Sales Data, from the results of daily sales each month, a recap will be made and the number of sales results is added up each month.

3. Annual Sales Data, in the form of results from daily sales, and monthly each year, each year the admin will make an overall recap and print an annual report to be given to the leader.

4. Stock reports, including data on items that are still there from the remaining sales, stock reports are used to view data on items that are still there.

Relationships are relationships between tables that represent relationships between objects in the real world [11]. Relationships are relationships that occur in a table with others that represent relationships between objects in the real world and function to regulate the operation of a database [12]. The Relationship Between the Tables is shown in Figure 2 below.

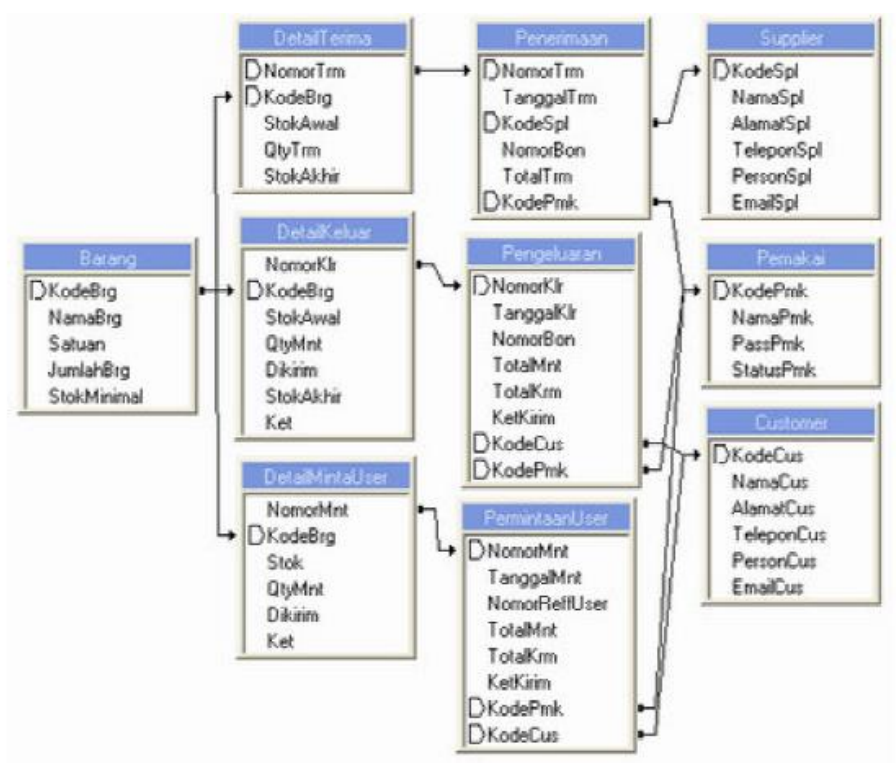

Fig.5. Relations Databases

The use of desktop-based product ordering and sales systems at the Tengku Diujung Restaurant, seen from the design of the application in the form of an application display. The following is the design result in the form of an application shown below. The login form is used as system security from abuse of access rights, so that data security can be guaranteed. Here the user is asked to enter a user name and password to be able to access further data. For more details, the login process can be seen in the image below. 


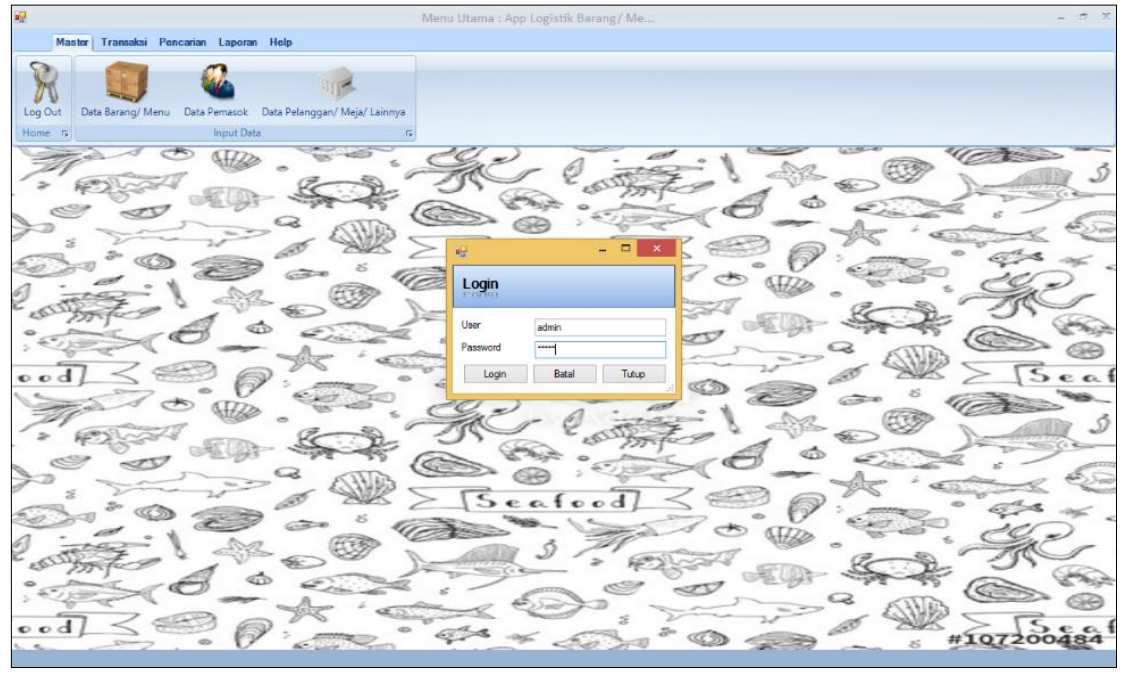

Fig.6. Login Form Display

In the form below is the main menu form which contains the master menu display, transactions, searches, reports, and assistance. Computer users just need to click the desired menu icon to see what is in the file.

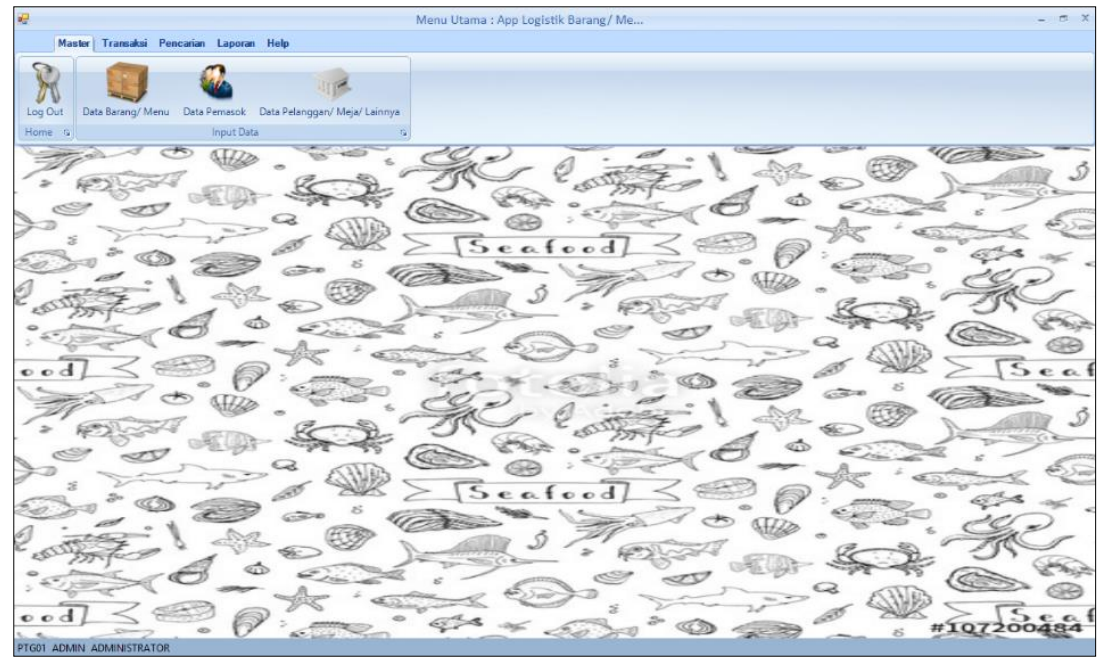

Fig.7. Main Menu Display

In the form below is a menu for adding item data, in this form you can change and delete item data. In this form, it consists of code, name, unit and quantity.

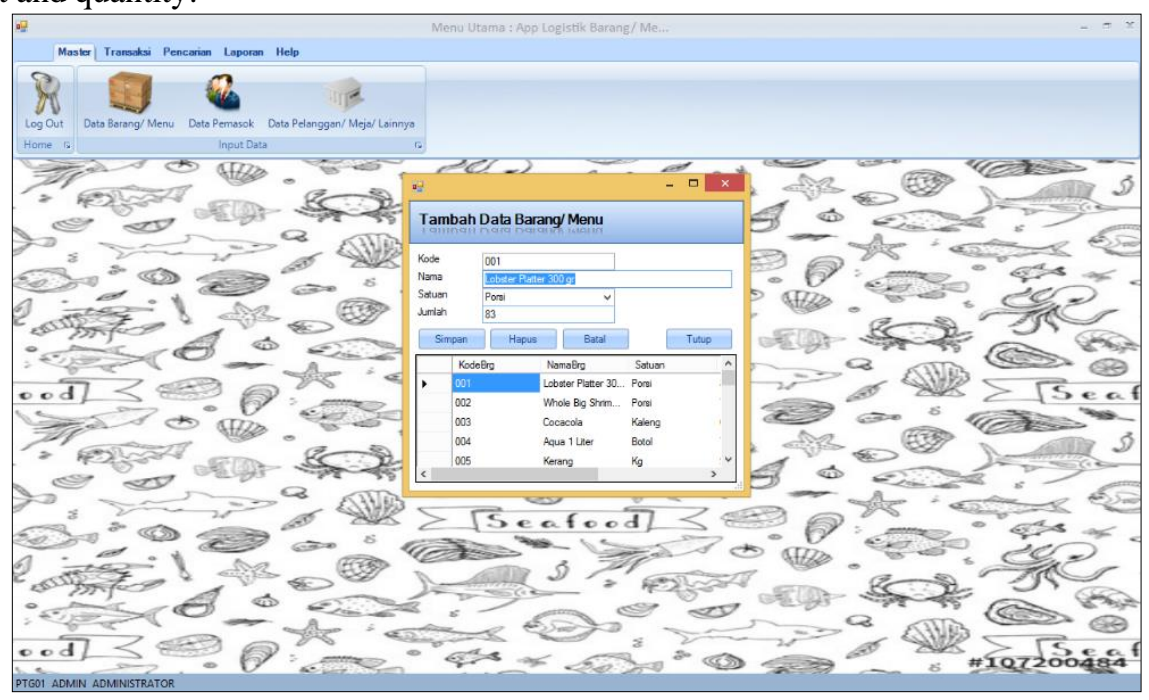

Fig.8. Display Item Data Form 
In the previous output, a form is displayed such as a printed form of receipt, ordering, and expense or sale of goods and can be displayed in daily, monthly and annual reports.

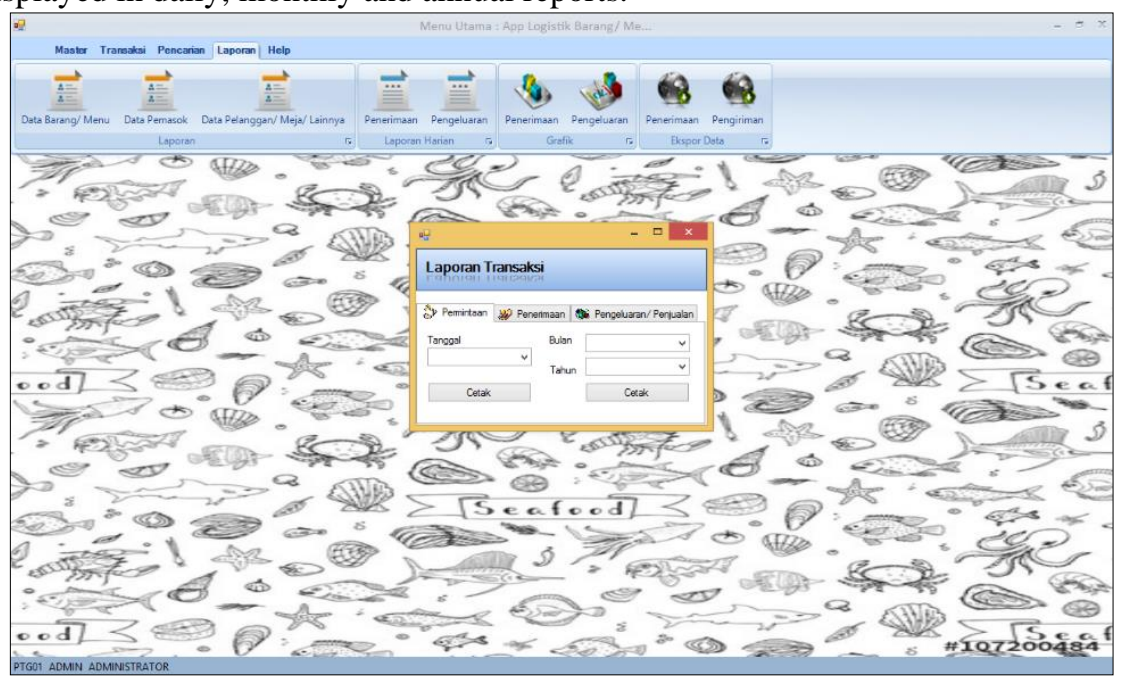

Fig.9. Print Goods Receipt Form

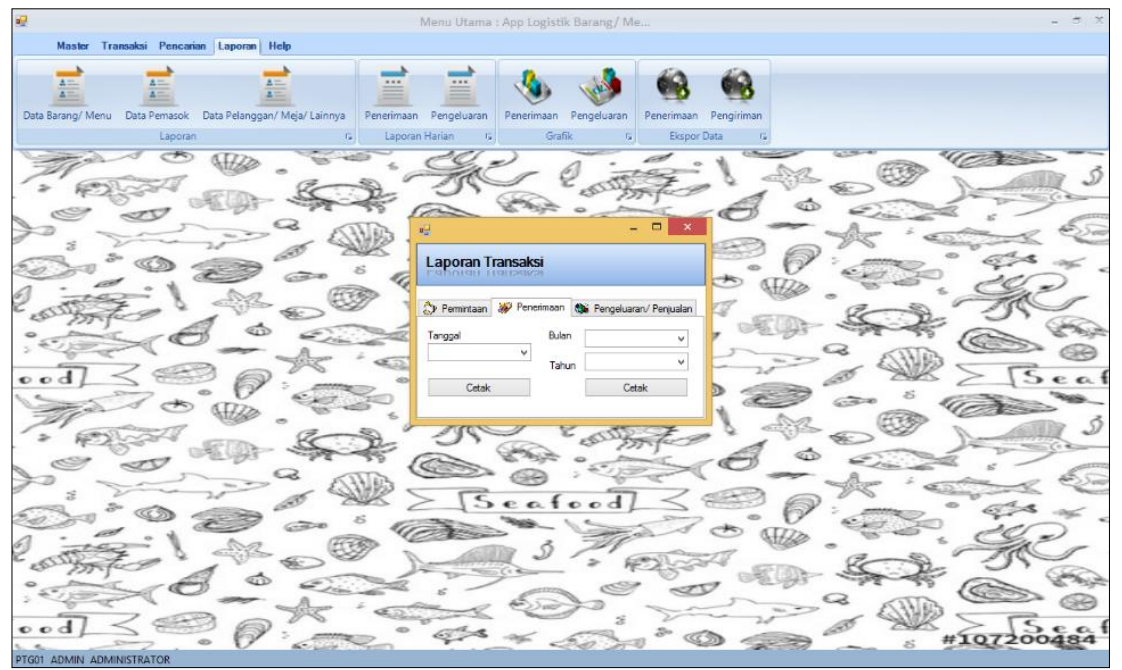

Fig.10. Print Order Form

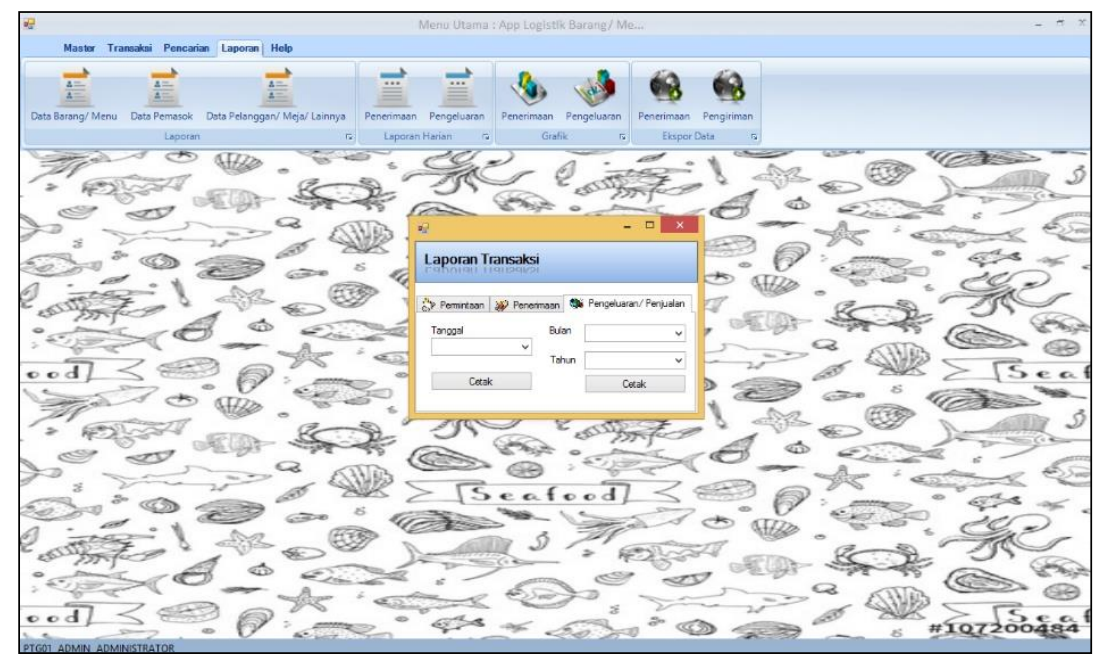

Fig.11. Form Print Issuance / Sale of Goods 


\section{Conclusion}

From the results of the discussion about "Inventory Information System at the Tengku Diujung Restaurant (Simeulue Regency)" the authors can draw the following conclusions:

a) The result of this research is the flight of an Inventory Information System application with 9 (nine) input forms consisting of; data on goods, suppliers, customers, receipts, expenses, stocks, transactions, and application users. There are 6 (six) output designs consisting of; goods data, suppliers, customers, receipts, expenses, and stock reports.

b) The use of a system that is still manual has limitations in selling goods. With this information system, it is easier for the restaurant to present information about revenue, ordering, and sales data to its customers. Even though it requires a large amount of money, it is worth the ease with which it is obtained.

c) By designing this application it will speed up the creation of reports of receipts, orders, and sales.

\section{References}

[1] Andoyo, Andreas, Siti Mukodimah, and Andino Masaleno. "Implementasi Mobile Commerce Untuk Meningkatkan Pendapatan Anggota Koperasi Gentiaras Pringsewu." JTKSI (Jurnal Teknologi Komputer dan Sistem Informasi) 3.1 (2020): 37-41.

[2] Efita, Wetri. "Perancangan Sistem Akuntansi Persediaan Barang Pada Toserba Milenium Pekanbaru Dengan Program Ms. Access 2007." Jurnal Ilmu Komputer dan Bisnis 9.1 (2018): 1946-1976.

[3] Liu, Xiaoming, et al. "Co-authorship networks in the digital library research community." Information processing \& management 41.6 (2005): 1462-1480.

[4] Mellon, Constance A. "Library anxiety: A grounded theory and its development." (1986).

[5] Kuhlthau, Carol Collier. Seeking meaning: A process approach to library and information services. Vol. 2. Westport, CT: Libraries Unlimited, 2004.

[6] Burgess, Robert G. In the field: An introduction to field research. Routledge, 2002.

[7] Burgess, Robert G., ed. Field research: A sourcebook and field manual. Vol. 4. Routledge, 2003.

[8] Gillham, Bill. Research interview. A\&C Black, 2000.

[9] Goldreich, Yair. The climate of Israel: observation, research and application. Springer Science \& Business Media, 2012.

[10] Clark, Andrew, et al. "Learning to see: lessons from a participatory observation research project in public spaces." International journal of social research methodology 12.4 (2009): 345-360.

[11] Perfetto, Livia, et al. "SIGNOR: a database of causal relationships between biological entities." Nucleic acids research 44.D1 (2016): D548-D554.

[12] Dey, Debabrata, Veda C. Storey, and Terence M. Barron. "Improving database design through the analysis of relationships." ACM Transactions on Database Systems (TODS) 24.4 (1999): 453-486. 